\title{
Low metabolic activity of biofilm formed by Enterococcus faecalis isolated from healthy humans and wild mallards (Anas platyrhynchos)
}

\author{
Włodzimierz Meissner • Tomasz A. Jarzembowski • \\ Hanna Rzyska • Claudia Botelho • Anna Palubicka
}

Received: 14 July 2012 / Accepted: 23 January 2013 /Published online: 14 February 2013

(C) The Author(s) 2013. This article is published with open access at Springerlink.com

\begin{abstract}
It is widely known that Enterococcus faecalis virulence is related to its biofilm formation. Although Enterococci are common commensal organisms of the gastrointestinal tract, the difference between commensal and pathogen strains remain unclear. In this study, we compare the biochemical profile of the biofilms formed by two groups of medical and two groups of commensal strains. The medical strains were isolated as pathogens from infections of urinary tract and other infections (wounds, pus and bedsores), and the commensal strains were taken from faeces of healthy volunteers and faeces of wild mallards (Anas platyrhynchos) living in an urban environment. The properties of biofilms formed by medical and commensal strains differed significantly. Commensal strains showed lower metabolic activity and glucose uptake and higher biofilm biomass than the medical ones. Consistent with glucose uptake experiments, we found that the glucose dehydrogenase gene was more expressed in
\end{abstract}

\section{W. Meissner $(\bowtie) \cdot$ H. Rzyska}

Avian Ecophysiology Unit, Department of Vertebrate Ecology and Zoology, University of Gdańsk, ul. Wita Stwosza 59, 80-308 Gdańsk, Poland

e-mail: w.meissner@univ.gda.pl

T. A. Jarzembowski

Department of Medical Microbiology, Medical University

of Gdańsk, ul. Do Studzienki 38,

80-227 Gdańsk, Poland

C. Botelho

IBB-Institute for Biotechnology and Bioengineering, Centre of Biological Engineering, University of Minho, Campus de Gualtar, 4710-057 Braga, Portugal

\section{A. Pałubicka}

Department of Laboratory and Microbiological Diagnostics, Kościerzyna Medical Center, ul. Piechowskiego 36, 83-400 Kościerzyna, Poland medical strains. These results indicate that higher metabolic activity and lower protein concentration of E. faecalis cells within biofilms are formed during infections.

Keywords Enterococcus faecalis strains · Biofilm · Metabolic activity $\cdot$ Protein concentration

\section{Introduction}

Enterococci are common commensal organisms of the gastrointestinal tract (Mohamed et al. 2004). On the other hand, Enterococcus faecalis is one of the most common causes of serious nosocomial and urinary tract infections (Sood et al. 2008). Despite many studies and recognition of virulence factors (e.g. Eaton and Gasson 2001; Furumura et al. 2006; Gülhan et al. 2006; Jarzembowski et al. 2009), processes that determine host-Enterococcus relationships remain poorly understood. Enterococci virulence could be related to biofilm formation (Parsek and Singh 2003; Sood et al. 2008). In the biofilm, cells are organised into structured communities enclosed within a matrix, and such a structure is phenotypically different from that formed by planktonic cells. Biofilm cells are more resistant to host defences and display a significant decrease in susceptibility to antibiotics (Costerton et al. 1999). The formation of cells occurs in response to a variety of cues, including high cell density, nutrient deprivation and physical environmental stress (O'Toole et al. 2000). Bacterial biofilm causes significant problems in many areas, both in the treatment and prevention of infections (e.g. persistent and recurrent infections as well as device-related infections) (Donlan and Costerton 2002). Enterococcus faecalis is capable of colonizing a wide range of hosts and environments showing great genome plasticity and diversity (Aakra et al. 2007). However, 
differences between an enterococcal pathogens and an apparently safe commensal strains is unclear and little is known about differences in biochemical properties between commensal and pathogenic strains (Eaton and Gasson 2001; Shiloach et al. 2010).

Our study aims to compare metabolic activity and biofilm composition of pathogenic and commensal $E$. faecalis strains with special emphasis on those isolated from wild birds.

\section{Materials and methods}

\section{Bacterial strains}

A total of 65 strains of E. faecalis were examined, including 32 commensal and 33 medical strains. Seventeen strains from the second group were isolated from urinary tract infections (UTI) (urine and swabs of urinary tract) and 16 strains from other infections (wounds, pus and bedsores), and were all taken only from humans. These samples were collected in the Kościerzyna Medical Centre. The commensal strains were isolated both from humans (faecal samples from 16 volunteers) and from wild birds living in urban environments (faecal swabs taken from the cloaca of 16 mallards Anas platyrhynchos caught in Gdańsk). Isolates were identified and recognized as a different E. faecalis strains by ID 32 STREP (bioMérieux).

For determination of biofilm dry weight, protein concentration and biofilm metabolic activity as well as cell enumeration of all four groups of strains were taken into account. For detection of glucose dehydrogenase gene expression, commensal strains from human and mallard faeces and strains from urinary tract infections were chosen. Additionally, two strains from urinary tract infections, two from human faeces and two from mallard faeces were randomly chosen for analysis of growth curves.

\section{Determination of biofilm dry weight}

Biofilms formed in a sterile well plate after $72 \mathrm{~h}$ were scraped from the bottom of the well, suspended in $1 \mathrm{ml}$ of $0.9 \% \mathrm{NaCl}$ and sonicated for $2 \mathrm{~min}$ on ice. Whole volume of biofilm solution was carefully inoculated into previously weighed cellulose membrane with pore size $0.2 \mu \mathrm{m}$ (Whatman, Kent, UK). The membrane was placed at $56{ }^{\circ} \mathrm{C}$ for $2 \mathrm{~h}$ and weighed again. Biofilm dry weights were obtained as the differences between these two measurements. As a negative control, a membrane inoculated with sterile $0.9 \% \mathrm{NaCl}$ and dried as a sample was weighed. The result was presented as a biomass of the biofilm per $1 \mathrm{~cm}^{2}$ of its surface.

\section{Cell enumeration}

Biofilms formed in a sterile well plate after $72 \mathrm{~h}$ were scraped from the bottom of the well, suspended in $1 \mathrm{ml}$ of $0.9 \% \mathrm{NaCl}$ and sonicated for $2 \mathrm{~min}$ on ice. Then, $1 \mu \mathrm{l}$ of the sonicated biofilm sample was diluted in $10^{3}$ and $10^{6} \mu \mathrm{l}$ of sterile $0.9 \% \mathrm{NaCl}$. Next, $10 \mu \mathrm{l}$ of diluted sample was plated onto agar plates and incubated overnight $(18-20 \mathrm{~h})$ at $37^{\circ} \mathrm{C}$. Inoculum of viable cells in the biofilm was determined by the enumeration of colonies on the agar as colony-forming units per $1 \mathrm{mg}$ of biofilm (CFU/mg) and per $1 \mathrm{~cm}^{2}$ of biofilm surface $\left(\mathrm{CFU} / \mathrm{cm}^{2}\right)$.

\section{Determination of protein concentration}

Protein concentration in the biofilm was determined using the BCA Protein Assay Kit (Pierce, USA). Biofilms formed in a sterile well plate after $72 \mathrm{~h}$ were scraped from the bottom of the well, suspended in $1 \mathrm{ml}$ of $0.9 \% \mathrm{NaCl}$ and sonicated for $2 \mathrm{~min}$ on ice. Then, $20 \mu \mathrm{l}$ of sonicated biofilm was sampled and the microplate procedure was used according to the manufacturer's instructions. The result was presented per $1 \mathrm{~cm}^{2}$ of biofilm-forming surface and $1 \mathrm{mg}$ of the biofilm.

\section{Determination of biofilm metabolic activity}

Metabolic activity was measured by glucose uptake, reduction of the XTT and glucose dehydrogenase gene expression. Measuring glucose uptake was performed as described earlier by Cerca et al. (2005) with a minor modification. Briefly, cells in sterile 6-well plates (TRP, Switzerland) were filled with $3 \mathrm{ml}$ of Brain Heart Infusion (BHI) and inoculated with $10 \mu \mathrm{l}$ of an 18-h culture normalised to an optical density of 0.5 . As a control, additional wells were filled with sterile BHI. After $24 \mathrm{~h}, 2 \mathrm{ml}$ of medium was replaced with fresh broth. The culture was terminated after $72 \mathrm{~h}$, the medium was aspirated and wells were washed with sterile $0.9 \% \mathrm{NaCl}$. Next, $1 \mathrm{ml}$ of $0.1 \%$ solution of glucose was added to each well and the plate was incubated for another hour at $37{ }^{\circ} \mathrm{C}$. After incubation, $10 \mu \mathrm{l}$ was aspirated to measure glucose concentration. Glucose uptake was determined with Glucose TR kit (Spinreact, Spain), measured at $505 \mathrm{~nm}$ with an ELISA reader and calculated as the difference between initial $(0.1 \%)$ and final glucose concentration.

XTT assay was performed using flat bottom polystyrene plates (TRP). Bacterial strains were grown at $37{ }^{\circ} \mathrm{C}$ for $72 \mathrm{~h}$ in BHI. After incubation, the medium was aspirated and the wells were washed with $0.9 \% \mathrm{NaCl}$. The metabolic activity of the cells was determined with the Cell Proliferation Kit (XTT-based) (Biological Industries) according to the manufacturer's manual. This technique is focused on the metabolic activity of viable cells and involves the use of 
tetrazolium salts, including 5-cyano-2,3-ditolyl tetrazolium chloride (CTC) and 2,3-bis (2-methoxy-4-nitro-5-sulfophenyl)-5-[(phenylamino)carbonyl]-2H-tetrazolium hydroxide (XTT). The XTT assay is based on the reduction of the XTT dye to water-soluble formazan (Roehm et al. 1991). The absorbance of the cell supernatant is proportional to the metabolic activity of the cells. In this study, the absorbance was measured at $490 \mathrm{~nm}$ with an ELISA reader.

For FLOW-FISH detection of glucose dehydrogenase gene expression, Molecular Beacon (MB) probes (CGCGAT CCACCAGTCACGAATGATGCGATCGCG) were designed with the software package (Beacon Designer; Biosoft). The FLOW-FISH method allows the analysis of single/particular cells in the sample and thus the evaluation of heterogeneity in the bacterial population. FITC-labelled oligonucleotides were synthesized commercially (Metabion) and tested for specificity against the set of reference organisms. Molecular beacon probes were additionally labelled with Dabcyl'5 as a quencher. Enfl84 probe (Waar et al. 2005) targeting E. faecalis 16S RNA and nonsense sequence probe was used respectively as a positive and negative reference.

For hybridisation, the procedure described by Waar et al. (2005) was adopted and modified according to the previous pilot study (Jarzembowski et al. 2009). Briefly, the cell membrane was permeabilizated by incubation for $30 \mathrm{~min}$ at $37{ }^{\circ} \mathrm{C}$ in permeabilisation buffer (TE) consisting of $1 \mathrm{mg}$ lysozyme/ml (DNA Gdańsk). Then, the cells were suspended in $1 \mathrm{ml}$ of $0.9 \% \mathrm{NaCl}$ and sonicated for $2 \mathrm{~min}$ on ice. Finally, the cells were centrifuged for $5 \mathrm{~min}$ at $2,500 \mathrm{rpm}$, washed and suspended in $200 \mu \mathrm{l}$ PBS buffer. Subsequently, $200 \mu$ l hybridisation buffer containing a FITC-labelled probe (1 ng) was added. The probes were hybridised for $45 \mathrm{~min}$ at $\mathrm{Tm}$ temperature.

Fluorescence of particles was determined by a FACS Scan flow cytometer (Becton Dickinson, San Jose, CA, USA). Percentage unstained particles (no. FL $1<10 /$ no. FL1 $>10$ ) and mean fluorescence per particle (FL1/FSC) were analysed.

\section{Growth curves determination}

The isolates were grown on a Brain Heart Infusion Agar (BHIA) plate at $37{ }^{\circ} \mathrm{C}$ for $48 \mathrm{~h}$, after which they were inoculated in Brain Heart Infusion (BHI) at $37{ }^{\circ} \mathrm{C}$ with constant agitation $(120 \mathrm{rpm})$. In order to evaluate the kinetics growth, $200 \mu \mathrm{l}$ of the suspension was removed every hour and its optical density determined using a plate reader with a wavelength of $640 \mathrm{~nm}$.

\section{Statistical analysis}

Since a zero value was obtained in some cases, 0.001 was added to all data in order to enable log-transformation of 0 values. All data were $\log$-transformed $\left(\log _{10}\right)$ to normalise variables and a constant value of 3 was added to bring minimum values after transformation to above zero. Thus, the transformation followed the equation: $\mathrm{x}^{\prime}=\log _{10}(\mathrm{x}+0.001)+3$, where $\mathrm{x}$ is the original value and $x$ ' the value after transformation. Nested ANOVA were used in all analyses with the four group of strains (isolated as a pathogen from urine in urinary tract infections, isolated as a pathogen from other infections, isolated as a commensal from faeces of healthy volunteers and isolated as a commensal from faeces of birds living in urban environments) nested in two strain types (medical and commensal strains). Data obtained in percent scale was transformed using $\arcsin \sqrt{ } \mathrm{x}$ function after dividing the percentage by 100 . Statistical methods followed Zar (1996).

\section{Results}

Biochemical parameters of medical and commensal strains differed to a large extent. In the case of glucose uptake, XTT assay results and the number of colony-forming units $(\mathrm{CFU} / \mathrm{mg})$ the differences between the means were the highest and exceeded $40 \%$ (Table 1). Both medical and commensal strains showed a wide range of $\mathrm{CFU} / \mathrm{mg}$ and $\mathrm{CFU} / \mathrm{cm}^{2}$ values (Table 1 ), which means that densities of cells in the biofilm differed greatly.

Mean metabolic activity measured by XTT value per mg of biofilm (XTT/mg), mean amount of protein per $\mathrm{cm}^{2}$, and mean mass of biofilm per $\mathrm{cm}^{2}$ did not differ among the four strains (nested ANOVA: among strains within strain type, $p>0.05$ in all cases), but differed significantly between medical and commensal types of strains (nested ANOVA, $F_{1,61}=9.46, p=0.003$ for amount of protein per $\mathrm{cm}^{2}$, $F_{1,61}=6.09, p=0.016$ for mass of biofilm per $\mathrm{cm}^{2}$ and $F_{1,61}=10.21, p=0.002$ for XTT result per $\mathrm{mg}$ of biofilm). Mean XTT value per $\mathrm{mg}$ of biofilm in medical strains was higher than in commensal ones, but for the mean amount of protein per $\mathrm{cm}^{2}$ and mean mass of biofilm per $\mathrm{cm}^{2}$ of surface, the results were opposite (Fig. 1).

Differences in glucose uptake between medical and commensal strains occurred in relation to surface (nested ANOVA among strains, $F_{2,61}=5.42, p=0.023$ ) and to biofilm biomass (nested ANOVA among strains, $F_{2,61}=10.25$, $p=0.002$ ). In both cases ,strains isolated from urinary infections had higher mean values than strains isolated from human faeces (nested ANOVA and Neuman-Keuls post hoc test, $p<0.05$ ) (Fig. 2).

Mean values of $\mathrm{CFU} / \mathrm{mg}, \mathrm{CFU} / \mathrm{cm}^{2}$, amount of protein per mg and XTT value per cell did not differ among the four strain types (nested ANOVA: among strains within strain type, $p>0.05$ in all cases). 
Table 1 Mean values and ranges of biochemical parameters for medical and commensal strains measured in this study

\begin{tabular}{|c|c|c|c|c|c|}
\hline \multirow[t]{2}{*}{ Biochemical parameter } & \multicolumn{2}{|c|}{ Medical strains } & \multicolumn{2}{|c|}{ Commensal strains } & \multirow[t]{2}{*}{ Difference between means } \\
\hline & Mean & Range & Mean & Range & \\
\hline Biomass of biofilm $\left(\mathrm{mg} / \mathrm{cm}^{2}\right)$ & 0.259 & $0.042-0.542$ & 0.315 & $0.125-0.542$ & $19.2 \%$ \\
\hline $\mathrm{CFU} / \mathrm{mg}$ & 22.656 & $0.238-88.889$ & 11.504 & $0.077-38.095$ & $49.2 \%$ \\
\hline $\mathrm{CFU} / \mathrm{cm}^{2}$ & 4.922 & $0.069-16.667$ & 3.648 & $0.042-12.222$ & $25.8 \%$ \\
\hline Glucose uptake $\left(\mu \mathrm{g} / \mathrm{cm}^{2}\right)$ & 0.461 & $0.038-1.655$ & 0.270 & $0.000-1.358$ & $41.3 \%$ \\
\hline Glucose uptake ( $\mu \mathrm{g} / \mathrm{mg}$ of biofilm) & 1.072 & $0.046-8.521$ & 0.344 & $0.000-2.148$ & $68.2 \%$ \\
\hline Amount of protein $\left(\mu \mathrm{g} / \mathrm{cm}^{2}\right)$ & 0.052 & $0.003-0.228$ & 0.063 & $0.034-0.177$ & $14.3 \%$ \\
\hline Amount of protein $(\mu \mathrm{g} / \mathrm{mg}$ of biofilm) & 0.202 & $0.009-0.608$ & 0.217 & $0.090-0.663$ & $10.0 \%$ \\
\hline XTT result (AU/mg of biofilm) & 0.737 & $0.229-3.075$ & 0.417 & $0.162-1.007$ & $43.2 \%$ \\
\hline XTT result $\left(\mathrm{AU} /\right.$ cell $\left.\times 10^{5}\right)$ & 0.215 & $0.007-2.020$ & 0.324 & $0.007-3.248$ & $52.4 \%$ \\
\hline
\end{tabular}

$A U$ Absorbance units
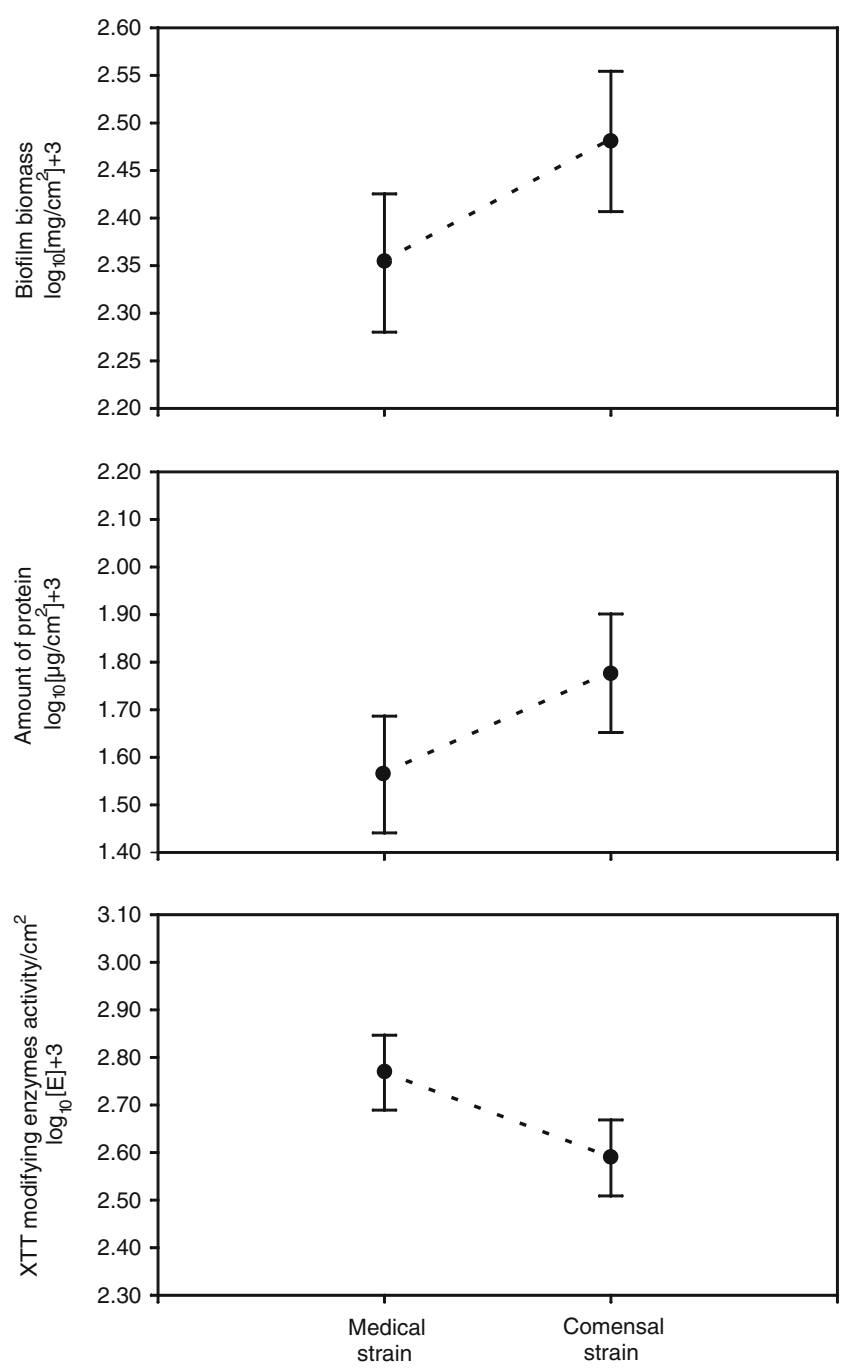

Fig. 1 Differences in biochemical properties of biofilm formed by commensal and medical strains. Vertical line $95 \%$ confidence interval around mean. All differences are statistically significant according to Neuman-Keuls post hoc test at $P<0.05$ (dotted line)
Between 20.2 and $98.7 \%$ of particles considered as cells were not bound by the probe targeting glucose dehydrogenase gene. The proportion was significantly lower in bird strains than those from urinary infections and human faeces (one-way ANOVA, $F_{2,35}=26.78, p<0.001$ and Newman-
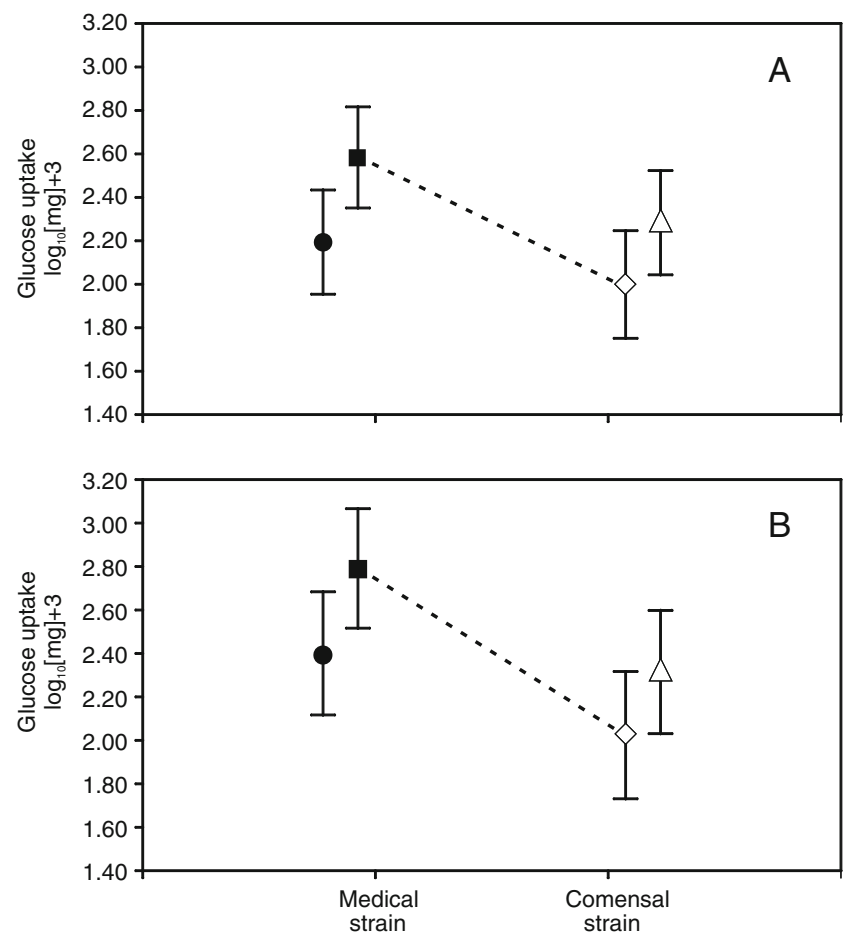

Fig. 2 Differences in glucose uptake between studied groups of strains in relation to biofilm surface (a) and biofilm biomass (b). Filled square strains isolated from patients with urinal infections, filled circle strains isolated from other non-urinal infections, open triangle strains isolated from birds, open diamond strains isolated from healthy people. Vertical line $95 \%$ confidence interval around mean. Dotted line joins strains that differed significantly according to Neuman-Keuls post hoc test at $P<0.05$ 
Keuls post hoc test, $p<0.05$ ) (Fig. 3). Also, mean fluorescence (FL1) of bound cells was lower in strains isolated from mallards comparing with both samples from humans (one-way ANOVA, $F_{2,35}=3.63, p=0.037$ ) with statistically significant differences between strains from bird and human faeces (Newman-Keuls post hoc test, $p=0.038$ ) (Fig. 3).

Differences were also observed in population growth rate. Medical strains have a similar behaviour, with a sharper exponential phase and reaching a higher plateau characteristic of the stationary phase. The exponential phase for all bacteria tested lasts $3 \mathrm{~h}$ from the moment of the inoculum (Fig. 4). Bird isolates were the strains with the most different behaviour, as their growth rate in exponential phase is much smaller than any other strain. Both faecal strains have a similar behaviour having an intermediate growth rate in comparison to medical isolates, which have the highest growth rate and bird isolates which have the lowest growth rate (Fig. 4).

\section{Discussion}

We showed that medical strains of $E$. faecalis display higher metabolic activity and lower biomass in biofims than commensal strains. Our results suggest that metabolic activity of enterococci does not correlate with higher cell concentrations in biofilms. It is possible that increases in EPS production might account for lower biomass in some biofilmforming strains. However, we have not investigated this point, as we have focused our attention on the cellular component of enterococcal biofilms.

We revealed that the medical strains of E. faecalis had higher metabolic activity and lower biomass of biofilm than the commensal strains. These results indicate that higher metabolic activity of enterococci was not related to higher concentration of cells in biofilm. Low biomass of biofilm can be the result of spread adaptation of the medical strain (Ahimou et al. 2007).

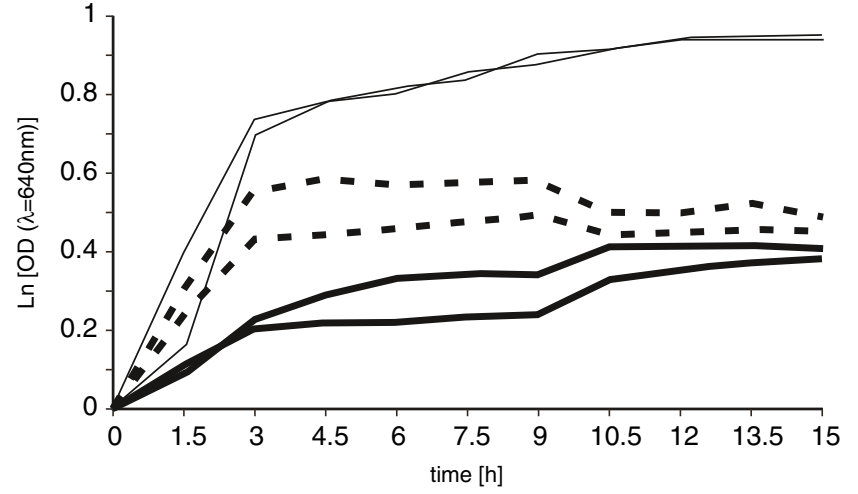

Fig. 4 Growth curves of two commensal strains from mallards (thick lines), two strains from humans' urinary infection (thin lines) and two commensal strains from human faeces (dashed lines) presented in semi-logarithmic scale

Glucose uptake was significantly higher in strains isolated from patients with urinal infections in comparison with those from healthy people. The same differences were observed at the transcription level (FLOW-FISH results) and when we compare growth curves. It is obvious that frequent cell division demands higher metabolic activity. On the other hand, the correlation of the results obtained by three different approaches means the difference between the studied strains is evident.

Some studies have shown that among E. faecalis, glucose supplementation enhances biofilm formation (Baldassarri et al. 2001), whereas other researchers have demonstrated glucose-mediated inhibition of biofilm production (Kristich et al. 2004). This divergence might be a result of a bimodal fashion of glucose-mediated biofilm formation, where greater biomass of biofilm would be created at the extremes of the environmental conditions, which could potentially provide the organism with a survival benefit in suboptimal growth conditions (Pillai et al. 2004). However, glucose uptake might result from cell density and correlate with the density of CFU in the biofilms (Cerca et al. 2005).
Fig. 3 Differences in mean percentage of unstained particles (a) and mean fluorescence per particle (b) between strains isolated from humans' urinary infections, human faeces and from wild mallards. Horizontal line mean, rectangle standard error, vertical line range. Statistically significant differences between strains were shown by arrows (Newman-Keuls post hoc test at $P<0,05)$. Numbers indicate sample size
[\%]

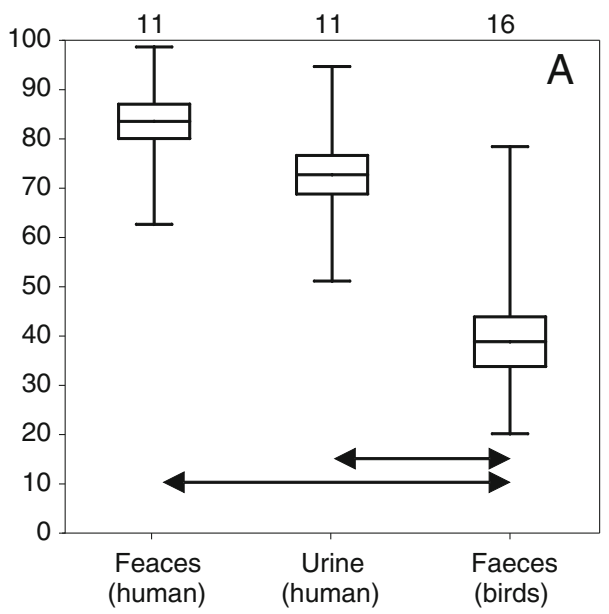

FL1

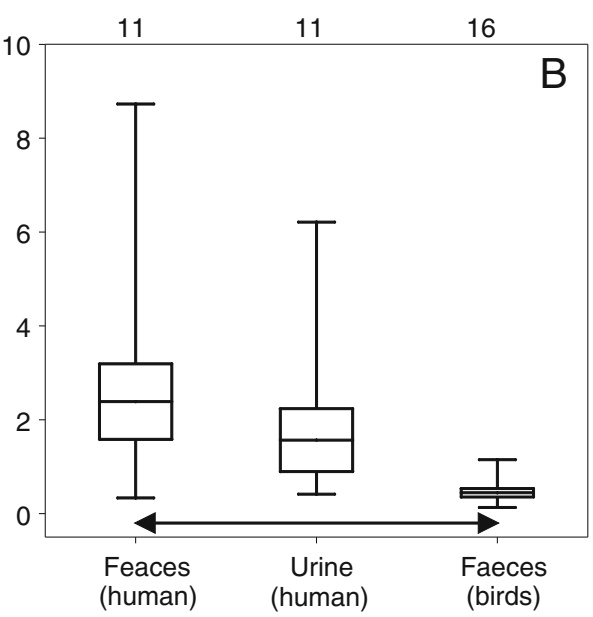


Although we showed statistically significant differences in biochemical properties between the medical and the commensal strains, it should be noted that environmental and clinical biofilms rarely, if ever, consist only of cells from a single species. Therefore, further studies are needed to analyse the influence of other species on E. faecalis biofilm. Moreover, when comparing results obtained from bird and human strains, differences in ammonia metabolism should be considered. Birds excrete urate instead of the toxic urea as do mammals. Urea in mammals is flushed out from the body with a great amount of water, while urate in birds is largely insoluble and uses very little water to be excreted (Goldstein and Skadhauge 1999). Thus, differences between strains collected from birds and from humans might be caused by biochemical adaptations to different media.

Not only glucose uptake but also lower amounts of protein found in the medical strains suggests slower growth of biofilm in these strain types in comparison with the commensal ones. This comes from the assumption that the concentration of proteins increases during biofilm development (Toledo-Arana et al. 2001; Tendolkar et al. 2004) and surface proteins can mediate biofilm formation (Geoghegan et al. 2010).

We have found marked differences in the biochemical properties of biofilms formed by strains of different origins. The medical strains formed thinner biofilm (lower amount of cells on the same area) with higher metabolic activity than the commensal strains. However, because of high divergence of features within groups of strains, it is still impossible to "forecast" bacteria-host relationships based on the biochemical properties of their biofilms.

Acknowledgments This work was supported by the Medical University of Gdańsk research grant (GUMed W-65) and was financed partly by University of Gdańsk research grant (BW 1440-5-0099-7). We are grateful to Katarzyna Żółkoś for her help in catching mallards and Magdalena Remisiewicz for correcting the English. Catarina Seabra helped in preparing assays.

Open Access This article is distributed under the terms of the Creative Commons Attribution License which permits any use, distribution, and reproduction in any medium, provided the original author(s) and the source are credited.

\section{References}

Aakra Å, Nyquist OL, Snipen L, Reiersen TS, Nes IF (2007) Survey of genomic diversity among Enterococcus faecalis strains by microarray-based comparative genomic hybridization. Appl Environ Microbiol 73:2207-2217

Ahimou F, Semmens MJ, Haugstad G, Novak PJ (2007) Effect of protein, polysaccharide, and oxygen concentration profiles on biofilm cohesiveness. Appl Environ Microbiol 73:2905-2910

Baldassarri L, Cecchini R, Bertuccini L, Ammendolia MG, Iosi F, Arciola CR, Montanaro L, Di Rosa R, Gherardi G, Dicuonzo G, Orefici G, Creti R (2001) Enterococcus spp. produces slime and survives in rat peritoneal macrophages. Med Microbiol Immunol 190:113-120

Cerca N, Pier GB, Vilanova M, Oliveira R, Azeredo J (2005) Quantitative analysis of adhesion and biofilm formation on hydrophilic and hydrophobic surfaces of clinical isolates of Staphylococcus epidermidis. Res Microbiol 156:506-514

Costerton JW, Stewart PS, Greenberg EP (1999) Bacterial biofilms: a common cause of persistent infections. Science 284:1318-1322

Donlan RM, Costerton JW (2002) Biofilms: survival mechanisms of clinically relevant microorganisms. Clin Microbiol Rev 15:167-193

Eaton TJ, Gasson MJ (2001) Molecular screening of Enterococcus virulence determinants and potential for genetic exchange between food and medical isolates. Appl Environ Microbiol 67:1628-1635

Furumura MT, Figueiredo PMS, Carbonell GV, da Costa Darini AL, Yano T (2006) Virulence-associated characteristics of Enterococcus faecalis strains isolated from clinical sources. Braz J Microbiol 37:230-236

Geoghegan JA, Corrigan RM, Gruszka DT, Speziale P, O'Gara JP, Potts JR, Foster TJ (2010) Role of surface protein SasG in biofilm formation by Staphylococcus aureus. J Bacteriol 192:5663-5673

Goldstein DL, Skadhauge E (1999) Renal and extrarenal regulation of body liquid composition. In: Wittow CG (ed) Sturkie's avian physiology. Academic, Oxford, pp 265-325

Gülhan T, Aksakal A, Ekịn IH, Savaşan S, Boynukara B (2006) Virulence factors of Enterococcus faecium and Enterococcus faecalis strains isolated from humans and pets. Turk J Vet Anim Sci 30:477-482

Jarzembowski T, Naumiuk Ł, Pałubicka A (2009) Prevalence of genes involved in pili-and biofilm formation and in vitro adherence properties of medical and faecal strains of Enterococcus faecalis isolated in Gdańsk. Microb Ecol Heal Dis 21:100-103

Kristich CJ, Li YH, Cvitkovitch DG, Dunny GM (2004) Esp-independent biofilm formation by Enterococcus faecalis. J Bacteriol 186:154-163

Mohamed JA, Huang W, Nallapareddy SR, Teng F, Murray BE (2004) Influence of origin of isolates, especially Endocarditis isolates, and various genes on biofilm formation by Enterococcus faecalis. Infect Immun 72:3658-3663

O'Toole GA, Kaplan HB, Kolter R (2000) Biofilm formation as microbial development. Annu Rev Microbiol 54:49-79

Parsek MR, Singh KP (2003) Bacterial biofilms: an emerging link to disease pathogenesis. Annu Rev Microbiol 57:677-701

Pillai SK, Sakoulas G, Eliopoulos GM, Moellering RC Jr, Murray BE, Inouye RT (2004) Effects of glucose on $f s r$-mediated biofilm formation in Enterococcus faecalis. J Infect Dis 190:967-970

Roehm NW, Rodgers GH, Hatfield SM, Glasebrook AL (1991) An improved colorimetric assay for cell proliferation and viability utilising the tetrazolium salt XTT. J Immunol Methods 142:257-265

Shiloach J, Reshamwala S, Noronha SB, Negrete A (2010) Analyzing metabolic variations in different bacterial strains, historical perspectives and current trends-example E. coli. Curr Opin Biotechnol 21:21-26

Sood S, Malhotra M, Das BK, Kapil A (2008) Enterococcal infections and antimicrobial resistance. Indian J Med Res 128:111-121

Tendolkar PM, Baghdayan AS, Gilmore MS, Shankar N (2004) Enterococcal surface protein, Esp, enhances biofilm formation by Enterococcus faecalis. Infect Immun 72:6032-6039

Toledo-Arana A, Valle J, Solano C, Arrizubieta MJ, Cucarella C, Lamata M, Amorena B, Leiva J, Penades JR, Lasa I (2001) The enterococcal surface protein, Esp , is involved in Enterococcus faecalis biofilm formation. Appl Environ Microbiol 67:4538-4545

Waar K, Degener JE, van Luyn MJ, Harmsen HJ (2005) Fluorescent in situhybridization with specific DNA probes offers adequate detection of Enterococcusfaecalis and Enterococcus faecium in clinical samples. J Med Microbiol 54:937-944

Zar JH (1996) Biostatistical analysis. Prentice-Hall, London 